\title{
Inadequate Agency and Appropriate Anger
}

\section{Daphne Brandenburg ${ }^{1}$}

Accepted: 14 February 2019 / Published online: 25 February 2019

(C) The Author(s) 2019

\begin{abstract}
Communication and cultivation accounts of responsibility (CC accounts) argue that blaming has an important communicative and agency-cultivating function when addressed at someone we consider to be deserving of blame. On these accounts, responsible agents are agents who can understand negative reactive attitudes and are (generally) sensitive to their moral-agency cultivating function. In this paper I examine our reproachful engagements with agents whose moral agency is underdeveloped or compromised. I discuss how these engagements compare to blaming on $\mathrm{CC}$ accounts and argue reproachful engagements can have an important communicative and agency-cultivating pointe. I then go on to propose an addition to CCaccounts that explains how underdeveloped and compromised agents can be held responsible. I will show how this addition resolves ambiguities in accounts from McKenna, Vargas and McGeer. I conclude the paper by anticipating an objection $\mathrm{CC}$ accounts could raise: that reproach and blame are co-extensive.
\end{abstract}

Keywords Responsibility · Moral agency · Cultivation · Scaffolding $\cdot$ Communication · Reactive attitudes $\cdot$ Children $\cdot$ Mental disorder

Our emotional engagements with compromised or underdeveloped agents are a central but under-theorized aspect of our interpersonal practices. Children and service users in mental health care are at times -temporarily or permanently- insufficiently able to comply with moral norms, and their carers then do not consider them blameworthy for transgressing them. Nonetheless their behaviour may give rise to negative emotions and experts consider it at times appropriate to reproach the service user or child (Brandenburg, unpublished). But in philosophy it is commonly assumed that negative reactive attitudes are inappropriate and best suspended if their addressee lacked ability to comply with moral norms (McKenna 2012; Vargas 2013; Wallace 1996). This paper aims to resolve this apparent tension between practice and philosophical theory.

Daphne Brandenburg

D.Brandenburg@ftr.ru.nl

1 Faculty of Philosophy, Theology \& Religious Studies, Radboud University Nijmegen, Erasmusplein 1, room 16.16, P.O. Box 9103, NL-6525 Nijmegen, HT, Netherlands 
In the First section of this paper I discuss how prominent Strawsonians like McKenna, Vargas, and McGeer respond to the blame-sceptic by claiming that blaming sentiments are justified if their addressee deserves it, because -in those cases- these sentiments successfully communicate moral censure to the addressee and (in a way that is derived from this communication) tend to cultivate moral agency in the addressee. Within this tradition, above threshold reason-responsiveness is the paradigm agency condition for being a deserving target of blaming sentiments. From now on I refer to those accounts that justify practices of deserved blaming on the basis of their communicative and (derived) moral agency cultivating purpose, as $\mathrm{CC}$ accounts.

I then move on to discuss how, in their focus on blame, $\mathrm{CC}$ accounts leave important parts of our moral practices unaddressed. This may explain the confusing and implausible suggestions about our engagement with underdeveloped or compromised individuals. In Second section I discuss reproach as a class of critical moral address and analyse how individuals whose reason-responsiveness is compromised or underdeveloped can be responsive to such address. In the Third section I analyse why and how some compromised and underdeveloped agents can be appropriately reproached without being deserving of blame.

I propose $\mathrm{CC}$ accounts include these individuals as persons who can, in some relevant, way be held responsible, and illustrate how this would resolve ambiguities in the accounts of McKenna, Vargas and McGeer respectively.

The Fourth section anticipates an objection to my proposal. On certain $\mathrm{CC}$ accounts one could argue that appropriate reproach and deserved blame are to be considered co-extensive. I argue this response would be problematic because it facilitates misrecognition of agency, complicates philosophical debate, and undermines a theory's critical potential.

\section{Communication and Cultivation; a Response to the Blame-Sceptic}

Since Strawson wrote 'Freedom and resentment', philosophers have pondered over the normative criteria for the appropriate experience and expression of blame towards a person (Strawson 2008). Strawsonians typically consider indignation or resentment to be the prototypical forms of blame. They ask under what conditions this blame is deserved by the target of these sentiments i.e. under what conditions the target is blameworthy. One of the main agreed upon criteria for being a deserving target of negative reactive attitudes is that the addressee did something that is morally objectionable.

Behaving in a morally objectionable manner is, however, not sufficient for being a deserving target of other people's blaming attitudes. There are further conditions that then need to be met for negative reactive attitudes to be a deserved response to a person(Smith 2007; Coates and Tognazzini 2013; Todd 2012). One of the main further conditions for being a deserving target of someone's resentment or indignation is what one may call the agency condition. The addressed person should have certain psychological abilities in order to be a deserving target of reproachful attitudes. Strawson writes about how we are invited to repudiate and withdraw our blaming sentiments when someone's abilities to comply with moral norms and expectations are underdeveloped or compromised (Strawson 2008, pp. 9-10).

Following Strawson, philosophers have taken up the challenge to identify the specific agential abilities that are necessary for being a deserving target of blaming sentiments. Most agree that a good account of the abilities that are required involves at least above-threshold 
responsiveness to moral reasons; only when a sufficiently reason-responsive agent fails to take into account moral considerations can this agent then be said to express the ill will or display the moral disregard that renders the person deserving of felt and expressed resentment or indignation. But if someone's reasons-responsiveness was underdeveloped or compromised, feeling and expressing blame towards the person would not be a deserved response (Fischer and Ravizza 1998; McGeer and Pettit 2015; McKenna 2012; Vargas 2013; Wallace 1996).

Reasons-responsiveness involves two types of abilities: the epistemic ability to recognize and weigh moral considerations and the volitional ability to guide one's actions in the light of these moral considerations. An agent is sufficiently responsive to reasons when she responds to these reasons in a range of relevantly similar circumstances. It is often unclear how large this range should be and which circumstances count as relevantly similar. I take it that the threshold range of relevantly similar circumstances is meant to single out a level of autonomy that allows us to say the person is already able to respond to the moral reasons that were disregarded, and of whom we may therefore expect more good will and regard. The person then need not go through any further development, training or therapy in order to be able to respond to the moral reasons that were disregarded in the type of circumstance in which they were disregarded. That an agent has this ability is suggested by the agent's responsiveness to these reasons in a range of relevantly similar circumstances.

But the sceptically inclined may still ask why above threshold responsiveness provides us with the level of competence required for deserved blame. In order to respond to the sceptic, further justifications need to be given to support the claim that expressing indignation or anger to someone who can - in a range of relevantly similar circumstances - do otherwise, can be deserved.

One powerful response to the sceptic is that these emotional exchanges of resentment and indignation are a form of moral address that -through communication- tends to cultivate reasons-responsiveness. They communicate that the person did something morally objectionable and tend to sustain and enhance the addressee's ability to discern these moral considerations and to act in the light of them i.e. they elicit uptake (Macnamara 2015). On these accounts, deserving targets of blaming sentiments are said to be generally understanding of what these emotions convey and expressing these emotions is said to render the addressee more able to discern and be motivated by these considerations in the future. These observations are taken to be broadly consistent with central evolutionary and naturalist accounts of the development and function of moral anger in psychology and cognitive science (Keltner and Haidt 2003; Lewis et al. 2010; McGeer 2011; Nichols 2007; Vargas 2013).

For those philosophers, a reactive attitude is an apt move in a conversation if it is directed at a person who can understand and respond to reactive attitudes as a form of moral address. Throughout this paper I will use the word appropriate to refer to this communicative aptness. It is generally assumed that individuals who have above threshold reason-responsiveness can typically also understand and respond to blame as a form of address, which is to say that if blame is deserved it is also appropriate.

Together, the value of communication and cultivation are purported to explain to the sceptic why felt and expressed blaming attitudes -to a competent agent- can be deserved: when they track an agent who is deserving of them, they communicate and tend to cultivate. According to some philosophers appropriate address of a person who expressed ill will or moral disregard, in itself provides the required further justification for why some people deserve blame (McKenna 2012). For cultivation theorists like Vargas and McGeer, the moral agency- 
cultivating outcome of appropriate address is the focal point of justification for deserved blame (McGeer 2014; McGeer and Pettit 2015; Vargas 2013).

\section{Attending to Reproachful Engagements with Underdeveloped or Compromised Agents}

In their response to the sceptic, the above accounts primarily focus on blame. These accounts thereby leave other relevant types of critical moral address under-analysed. Less charitably, other forms of critical moral address, on these accounts, are not only left unaddressed but also seem to be misrepresented. Strawsonians often seem to suggest that (sincere) critical and emotionally engaged forms of moral address are neither natural or desirable responses when an addressee lacks above threshold reason-responsiveness (e.g. Shoemaker 2007; Strawson 2008; Wallace 1996; Watson 1993). In reality the conduct of underdeveloped or compromised agents does affect us, and we do at times have critical moral conversations with them as a result of being negatively affected by their conduct. In this paper I argue such interactions can be appropriate and discuss how we should conceive of such reproachful engagements on CC accounts.

The sort of reproachful engagements I have in mind are in important ways akin to the types of blaming that are central to CC accounts. In this section I provide an account of reproachful attitudes that is similar to, but does not completely overlap with (what are typically considered to be) blaming attitudes. I then discuss how compromised or underdeveloped agents can be sensitive to the morally communicative function of such reproachful attitudes and therefore would be appropriately reproached even though they would not deserve to be blamed.

A reproachful attitude is an affective response to someone's behaviour that exists in an appraisal of this behaviour as norm-transgressive, and a bodily readiness to in some way challenge the agent, or interfere with the agent (Keltner and Haidt 2003; Lewis et al. 2010; Nichols 2007). Reproachful sentiments are thus tied to the (perceived) transgression of an interpersonal norm. They also typically manifest that we care about this norm.

Reproachful attitudes may be expressed by something as slight as a frown, a raised eyebrow or a serious stare. They may also be subtly couched in a surprised response or a question tinged with disapproval. Our expressions of reproach in response to other people's behaviour are incredibly multifarious, and people are typically quite sensitive to the variety of facial, verbal and bodily expressions of reproach. But it should be noted that reproach, as I understand it, constitutes critical address, engages the addressee, and calls for some sort of response from the addressee.

Obvious as this may seem, it is important to point this out because it distinguishes reproachful attitudes from so called 'attributability responses' (Shoemaker 2015). An attributability response does not necessarily serve to engage and address the person who elicited this response. These responses only concern an attribution of fault or of certain undesirable traits to the person. Such responses only morally evaluate a person, but they do not call for a response from the person who is evaluated. Typical examples of attributability responses are contempt, disdain or revulsion. I set such responses aside and only focus on emotional responses to a person that are associated with critical address and engagement. These responses do more than just critically evaluate the person; they also aim to address and engage the person. 
In this sense, reproachful attitudes are especially similar to blaming attitudes on $\mathrm{CC}$ accounts. Vargas for example writes that blame "is very much like a marking of morally salient considerations. It doesn't work by unfettered manipulation of behaviour disconnected from any invitation to reflect on the involved moral considerations (Vargas 2013, p. 202).' McKenna writes that blame, among other things, communicates our moral expectations and disapproval to the addressee (McKenna 2012, Chapter 7). These observations would also apply to reproachful attitudes more broadly. They are a response to morally objectionable conduct that communicates the relevance of certain moral considerations to their addressee and invites the addressee to reflect on what is morally acceptable and what not. Just like blame on $\mathrm{CC}$ accounts, a reproachful attitude is an affective response which, when expressed, communicates the relevance of some moral norm and invites the addressee to reflect on her conduct (e.g. McKenna 2012, Chapter 7; Vargas 2013, Chapter 8).

But reproachful attitudes are not identical to blaming attitudes. Blaming attitudes are a particular subcategory of the larger class of reproachful attitudes. The message of reproach, broadly conceived, can carry a wide range of contents. ${ }^{1}$ The communicative message of reproach, among other things, may convey that you did something that is unfair, disrespectful, or in another way morally objectionable within a given community. ${ }^{2}$ It aims to convey some type of disapproval to the person in response to her not complying with some interpersonal norms, standards or expectations that you have. It is in this regard that reproach, broadly conceived, is different from (most understandings of) blaming sentiments. Reproach can convey to the person that she acted objectionably without expressing that the person is deserving of blame and without attributing blameworthiness to the person. Contrary to blame, reproach does not necessarily also convey that we consider the addressee's conduct to be an expression of ill will or moral disregard which requires above threshold reasonresponsiveness. ${ }^{3}$

Some philosophers would probably object here that they do mean for the class of blaming attitudes to be co-extensive with reproachful attitudes. This seems counter-intuitive and inconsistent with most philosophical accounts of blame, but that need not be a problem if these philosophers mean to revise our understandings of blame. I will pay special attention to this objection at the end of the paper. For now I will set it aside and assume that there are forms of reproach that do not qualify as blaming.

In what follows I ask if and how compromised or underdeveloped moral agents can be sensitive to the communicative and moral agency cultivating function of these forms of reproach that are not blame. I will argue that they can be susceptible in at least two different ways. I first discuss how their responsiveness to a moral reason may be enabled by reproachful address and then consider how their responsiveness to moral reasons can be developed by reproachful address.

\footnotetext{
${ }^{1}$ Note also how other feelings, like sadness or laughter, may at times convey reproach and even blame.

${ }^{2}$ An angry response need not even have moral content. When one gets angry at a dog this probably only conveys a threat or command like: 'comply or I'll punish you!' Thanks to Shaun Nichols for this suggestion.

${ }^{3}$ According to a number of philosophers, blaming sentiments like resentment typically involve feeling personally aggrieved, threatened in one's standing or relationship (e.g. Hieronymi 2004; McKenna 2012, Chapter 3; Shabo 2012; Smith 2013; Wallace 1996). In comparison a reproachful attitude can also be more akin to frustration, annoyance or disapproval. If, for example, someone else pushes you when standing on a train platform during rush hour you may have an acute and local reproachful response to the person who pushed you(e.g. Deigh 2011). This reproachful response may then, for example, be maintained or reinforced if you realise that the person pushed you on purpose, and turn into a feeling of resentment.
} 
The examples of interpersonal reproach one reads about in the literature often concern a response to wrongful or morally untoward actions that have already taken place. In reality we also often respond reproachfully at the time that an action is taking place. I take it that intervening reproachful responses can render the addressee responsive to a moral consideration that one would not otherwise recognize or be moved by. To illustrate, consider what happens in the following scene from a Louis Theroux documentary on people with severe brain damage. Among the persons with brain damage who are followed in this documentary is a man called Earl. At one point, Louis is talking to Earl's mum when Earl suddenly comes bursting in and is verbally abusive to her. His mum starts crying, and tells Louis this abuse happens all the time. Louis looks at Earl and asks him if he has just been playing FIFA and lost. Earl confirms that he has. Louis then asks, 'You are taking this out on your mum, aren't you?' Earl doesn't respond. Louis adds: 'I think you should apologize to your mum.' Earl asks, 'Why? She doesn't care.' Louis then looks demonstratively at his mum (who is crying). Earl also looks at his mum, and then walks over, apologizes, and gives her a big hug (Pickup and Theroux 2016).

Earl is probably not sufficiently responsive to his mum's feelings in a range of relevantly similar circumstances. His mental capacities are severely impaired and he has been generally more abusive since his brain injury. It is likely that he fails to grasp what he is doing to people by behaving in this way when he does. This is also suggested by his remark that his mum 'doesn't care', even though she is crying right in front of him. Hence, recognizing the feelings and concerns of others as things that have bearing on how he should act doesn't seem to be something that Earl can be expected to do under circumstances like these. It is also hard for him to regulate his crankiness and to control for his impulse to take this out on others. His actions are better explained by an inability to notice and respond to certain moral considerations in these sorts of circumstances.

However, Louis responds reproachfully when he sees Earl acting in an abusive manner and gives expression to his disapproval when he addresses Earl. When we witness this interaction on the screen, we can tell that Louis is negatively affected by Earl's conduct and subtly expresses these feelings to him when calling him out. On my optimistic interpretation of this case, Earl then becomes appropriately responsive to his mum's distress because Louis has made this distress salient to him as a relevant moral consideration under the circumstances. Louis' reproach enabled Earl to respond to his mum's distress as a reason for providing her comfort and apology. Without it, Earl would not have been responsive to this moral consideration in this specific situation, nor in relevantly similar circumstances where third party reproach is absent. This reproach, in Earl's case, may also be unlikely to lead to the development of an independent ability to respond to these moral considerations in a range relevantly similar circumstances, but it enabled Earl's responsiveness to moral considerations right there and then.

One may of course refuse to go along with my optimism here. Maybe Earl is not touched by his mum's suffering at all, and only responds to Louis' reproachful sentiments because he wants Louis to like him, or feels threatened by him, or maybe his response is due to some other non-moral motivation. ${ }^{4}$ But even if this is what happens on this specific occasion, the possibility that someone's responsiveness to a moral consideration is at times enabled by an expression of reproachful sentiments is extremely likely. Think of all those typical situations in

\footnotetext{
${ }^{4}$ The distinction between moral and non-moral motivations may not be as robust as suggested here: moral and non-moral motivations may overlap and be linked to one another in intricate ways (e.g. Schwitzgebel 2017).
} 
which someone is (temporarily or permanently) unresponsive to the harm she is doing to others, but becomes responsive to it upon being reproached.

Some people, for example, have serious difficulty participating in meetings and presentations because they are not sensitive to the social dynamics of who may talk when and for how long. They respond to the speaker whenever an objection occurs to them and take up too much time in Q\&A sessions. The sort of moral considerations we generally think one should be motivated by in these types of contexts are possibly simply not detected, rather than disregarded, by the person. The fact that other people respond reproachfully to this behaviour can, however, enable responsiveness to the entitlement of others to speak and ask questions as well.

Such enabling forms of reproach are common. In schools and clinics, cooperative activities often need to be regulated by caregivers because the participants are not always sufficiently independently responsive to the needs and concerns of other people. Some children in school will continually try to get the attention of the teacher when the teacher is trying to explain something to another child, or a patient in a psychiatric ward may tend to become verbally abusive whenever he feels powerless or fearful. These people may under these circumstances be oblivious to the impact that their behaviour has on the feelings and concerns of others. Regulating this behaviour often involves some expression of felt reproach that triggers responsiveness to the moral concerns at stake.

Reproachful sentiments are also likely to be a form of feedback that fosters the development of moral responsiveness. To see how, imagine a four-year-old and his dad travelling by train. The child is very excited and points out everything he sees to his dad. In his excitement he gets louder and louder until he is basically screaming about everything he sees, and he repeatedly pushes against his dad's shoulder to gain his attention. The dad addresses his child reproachfully: 'Shh, quiet down! Look around you. Other people are working or reading and you are bothering them!' In response to this, the child looks at his dad with his eyes wide open and steals some glances around him. For the next 15 min he only whispers excitedly about everything he sees. After that, of course, he gets louder and louder again as he is - for the first time in his life - approaching some big impressive station full of trains and people and dogs and other exciting things.

The parent in our example is affected by the child's behaviour. The child is, after all, screaming very loudly, which is bothersome to him and to others, and the repeated pushing is a cue for anger too. Of course these things do not always arouse a parent's anger, but on some occasions they do and this is one of them. The dad then expresses these feelings by pointing out to his son that he shouldn't behave that way. His anger is conveyed to the child in his facial expression and in the tone of his voice.

At the age of four, the child is probably not yet able to recognize and respond to the moral considerations at stake. He is not yet sufficiently able to independently grasp and be moved by the relevant needs and concerns of others when travelling by public transport. The child does not yet have the habits or resources for control that adults have at their disposal, especially not when his enthusiasm takes over. Hence, the screaming child does not meet the two conditions for reasons-responsiveness.

But babies and young children do have sensitivities and inclinations that are the rudiments of or - depending on one's definition - precursors of the responsiveness to moral reasons (Gopnik 2009; Sagi and Hoffman 1976; Smetana 1989; Zahn-Waxler et al. 1992). Some of these seem to emerge without any relevant exposure to social feedback; infants already tend to 
sooth someone in pain and the differentiation between harming and helping emerges quickly (Bloom 2012).

But social feedback is central to the further development of moral responsiveness to different types of reasons across a variety of situations. This is for example the case where it concerns sensitivities that are informed by complex cultural and technological backgrounds and contexts that complicate the instinctive grasping of the moral import of one's behaviour (like the moral importance of being quiet on a train, saying 'thank you' to the local baker, or refraining from taking sweets and shiny toys from a store). The child cannot yet independently recognize how certain considerations have moral relevance in certain types of circumstances and a parent or carer has to help them in making these connections(e.g. Nichols et al. 2016).

Now, of course, not all forms of social feedback concern the feeling and expression of reproachful attitudes. It is not very helpful for a child's moral development to always respond reproachfully to any socio-moral transgression. The literature on moral development suggests that parents should ideally employ a variety of 'disciplining strategies' that are catered to the specific child, context and type of behaviour (Grusec and Goodnow 1994; Killen et al. 2005).

Reproachful attitudes have a place in this variety of strategies and interactions. Research suggests that a mother's tendency to respond reproachfully in response to anti-social facts successfully fosters moral development (Grusec et al. 1982). It is also suggested that the affective character of a corrective response helps to motivate a child to respond to the reasons that parents give them and helps to stress the moral importance that parents attach to certain standards (Clarke-Stewart 1973; Grusec and Goodnow 1994; Hoffman 1983; Killen et al. 2005). Children - in some sense - pick up on what reproach-expressions convey, and this understanding feeds into the development of their moral responsiveness.

Hence, though the screaming child in the train lacks above-threshold responsiveness to moral considerations under these circumstances, the child is (either in a non-moral or minimally moral sense) responsive to his dad's emotions. If parents get angry, this - at the very least - conveys to a child that something is not $\mathrm{OK}$, and if they praise the child this signals that their behaviour is OK. The child's emotional responsiveness already, then, renders the expression of parents' reproachful attitudes appropriate because it is a successful form of address and cultivation. As time proceeds, the child will be increasingly able to reflectively connect these expressions to moral values and standards.

The different ways in which parents express and communicate their reproachful attitudes reflect the different developmental stages. For very young children, these communicated feelings and responses are usually purely affective and directive in character, whereas these feelings are accompanied by instructions and explanations as soon as the child is old enough to be receptive to those. When older children have developed a reasonable level of reflective awareness of moral standards, a parent's response to transgressions tends to be affectively reproachful in character without being accompanied by instructions and explanations (Killen et al. 2005, chapter 9). Note that the child's awareness in these situations is probably still not sufficient for above-threshold reasons-responsiveness and blameworthiness on all accounts. Nevertheless, all of these felt and expressed responses to socio-moral transgressions can be evaluated as appropriate in the light of what they convey and the moral development that they foster.

Average adults can also fall below the threshold responsiveness in a range of certain types of circumstances. There are, for example, a number of arguments in the literature in favour of responsibility-relevant impairments of volitional control over implicit attitudes (Antony 2016; Brandenburg 2016; Huebner 2016; Levy 2016). And people's abilities to recognize moral 
considerations may also be compromised in certain types of circumstances. Calhoun, for example, discusses how many people non-culpably fail to recognize that their behaviour is in some sense sexually or racially oppressive when they live in a society that is guided by norms and standards that foster this oppression. She also argues that one can nevertheless be justified in using reproach as a tool for social change in that context (Calhoun 1989). McKenna agrees with her but notes that, though justified, these attitudes would not be fitting as 'moral address' to the agent, given the agent's inabilities to recognize forms of oppression (McKenna 2017). But this form of address may still be appropriate in so far as it communicates that their behaviour is sexually or racially oppressive, and potentially scaffolds or develops the person's responsiveness to racial or sexual oppression even if the person is not deserving of blame, i.e. despite a below threshold ability to respond to moral considerations one may still be receptive to reproachful attitudes and therefore appropriately be addressed by them. If, say, a married woman in the 1960s angrily confronted her husband with the injustices he was unwittingly subjecting her to, this form of address may enable or develop his responsiveness to these concerns. His sensitivity to what her feelings convey to him would then render him -in the communicative sense of the word- an appropriate addressee of reproach, but he is not thereby also a deserving candidate of blame.

\section{An Addition to CC Accounts}

If the skills for responding to moral considerations and responding to blame are pluralistic in character and come in degrees, it is plausible to assume that many of those who fall below the threshold for reason-responsiveness may be in possession of some preliminary aspects of these skills and/or have these skills to some degree. This assumption finds further credence when we look at our actual interactions with underdeveloped and compromised agents, and observe what they can do.

The agents discussed in the last section clearly have some agential abilities. They are responsive to a moral message that reproach (broadly conceived) conveys. And because this reproach conveys the salience of a moral consideration, the agents are also responsive to a moral consideration when reproached. But it seems wrong to say of them that they are already sufficiently able to respond to these moral considerations by themselves. They lack the type and level of agency required for blameworthiness for their conduct. Without reproach as a form of enablement and development of this responsiveness, these agents are hardly ever attuned to such reasons under relevantly similar circumstances (where this does not include those circumstances in which one's responsiveness is enabled by another person's reproach). I propose $\mathrm{CC}$ accounts add an agency criterion to their theories that would -all other things being equal- suffice for being an appropriate addressee of forms of reproach that are not blame.

On the picture I propose, above threshold reason-responsiveness still is a necessary agency condition for being a deserving addressee of blame. But in addition to this, the minimally required agency condition for being an appropriate addressee of reproach more broadly conceived is responsiveness to reproach. This condition does not refer to abilities to abide by moral norms, but specifically refers to abilities to understand and respond to moral conversation. An agent is already responsive to reproach when her responsiveness to a moral consideration can be enabled or developed through communication of reproachful attitudes. Compared with the above threshold reasons-responsiveness requirement, the condition of reproach-responsiveness is met if: 
Being addressed by reproachful attitudes a) renders the moral reasons one did not respond to (more) salient to the person now or in the future and b) may motivate the person to respond to this reason now or in the future.

If communication and cultivation models are right, then above threshold reasonresponsive agents are typically also responsive to reproach. But responsiveness to reproach in itself falls below the threshold of responsiveness to reasons required for blameworthiness. The agents discussed in Section 3 are, for example, only responsive to reproach and not (or not yet) independently sensitive to the moral considerations that this reproach renders salient. They are appropriate addressees of reproach, but not deserving targets of blame.

I relatedly propose that there is then an important way in which reproach-responsive agents are responsible, and may be held responsible for morally objectionable behaviour. They may be held responsible in so far as they may be called out on this behaviour and may be called upon to do better now or in the future. They are responsible in so far as they are capable of minimal moral communication and sensitive to the moral agency-cultivation of reproach. This forward-looking sense in which these agents are responsible and can be held responsible, renders them in a relevant way participants in our moral practices and appropriate subjects for moral address (Brandenburg 2017 vs. Pickard and Ward 2013). Below I will discuss how reproach-responsiveness clarifies and supplements the theories of respectively Michael McKenna, Victoria McGeer and Manuel Vargas.

McKenna, in agreement with Watson, says that one of the crucial abilities that an exempted agent lacks and a responsible agent has is 'a capacity to be addressed through the morally reactive attitudes and their attendant practices.'(McKenna 2012, Chapter 4) On his account an exempted agent is ill equipped to understand what is communicated through the manifestation of blaming attitudes.

But young children and cognitively compromised agents can often be addressed through expressions of reproachful attitudes. The reproachful expressions in the above-discussed scenarios are, for example, communicatively felicitous. And these agents may even be able to understand (parts of) the message of the deeper forms of reproach that we characterize as resentment and indignation (despite the fact that they are not deserving of those responses).

Does this then mean that these agents are not exempted from responsibility on McKenna's account? Because they can in an important way participate in a moral conversation -they can understand and respond to other people's reproach- it seems they are not suitable candidates for McKenna's interpretation of Strawsonian exemption.

But they are not fully responsible agents on McKenna's account either because they do not meet the agency criterion for being a deserving target of blaming sentiments. The criterion for blameworthiness, on his account, is that a person knows her action is wrong, and performs it freely (McKenna 2012, Chapter 4). But how could an agent not be exempted, but not be responsible either? McKenna's account is unclear when it comes to the question of how we are to conceive of agents that are reproach responsive but not (above threshold) reason-responsive.

By allowing for my supplement McKenna could include a class of agents for whom reproach could be a communicatively appropriate form of moral address. Reproachresponsive agents can in a relevant way participate in responsibility practices because these agents can understand and respond to reproach. He could also still maintain that these agents are not always appropriate and deserving addressees of the particularly strong forms of reproach that qualify as blame. 
McKenna could explain this because the message of blame is different from the message of milder forms of reproach. Blame conveys -among other things- that we attribute to you a type of ill will or disregard for others that requires above threshold reason responsiveness. This would only be warranted if the person meets the required threshold. When an addressee is reproach responsive only, milder forms of reproach would be the warranted and communicatively felicitous manner of address.

Reproach-responsiveness is also a relevant addition to Vargas' agency-cultivation model. Vargas paints 'a picture of desert on which responsible agents deserve reactions to their blameworthy actions because such reactions help aid agents in their self-governance in light of moral considerations (Vargas 2013, Chapter 8).' According to Vargas, in the ordinary case, blaming 'tends to push the target's attention to considerations that others perceive as morally salient. In this way, blame connects agents with psychologies like ours to moral considerations (Vargas 2013, Chapter 8).'

Please note how similar this description is to the effect that reproachful attitudes tend to have on a reproach-responsive addressee. By reproaching a reproach-responsive addressee, one also pushes the addressees attention to considerations that others perceive as morally salient and this address typically has a derived agency-cultivating function too. In this regard appropriate reproach only differs from deserved blaming in so far as it develops or enables rather than maintains or enhances the addressee's agency.

But when it comes to the ways in which we can appropriately make moral considerations salient to non-culpable agents who fall below the threshold for reason-responsiveness, Vargas is silent. He only provides a brief and slightly puzzling description of our responsibility attributions to children. He claims that children below the reasons-responsiveness threshold are typically subject to feigned responsibility attributions (Vargas 2013, Chapter chapter 7, section 8). I don't think our interactions with children or compromised agents are typically 'feigned' interactions. Surely when we reproach children, this reproach is not always heartfelt. The naughty behaviour of a little child at times makes us laugh rather than feel reproachful. In such cases we may nonetheless pretend to feel reproachful. But there are also times when we really do feel reproachful towards children and express these feelings to them.

What is it then that Vargas is getting at when he says our responsibility attributions to children are generally 'feigned'? My suspicion is that Vargas would describe the reproach of a child as a feigned responsibility attribution because he assumes this is a form of holding someone responsible and also assumes that all forms of holding responsible are blame attributions. We rarely believe that young children are sufficiently reasons-responsive to be deserving of blame for what they did. What is in fact feigned according to him is, then, not so much the emotional expression but rather the blameworthiness attribution.

He hereby overlooks the possibility that we can genuinely reproach someone without also blaming the person. An attribution of blameworthiness and above-threshold reasons-responsiveness is not necessarily implied in expressing reproachful attitudes to someone. The child thereby is responsible in some of Vargas's sense of the word, because the child is sensitive to the cultivation function of reproachful attitudes. This sense of 'responsibility' renders the child an appropriate target of these attitudes. This theory would therefore benefit from including reproach-responsiveness as a type of agency that suffices for some forms of holding responsible i.e. that suffices for forms of genuine reproach that do not amount to blame.

Also on McGeer's cultivation-model it is not immediately clear how we are to think of children or compromised agents who are responsive to reproach but are not independently able to respond to moral reasons. According to McGeer, 'reactive emotions are those emotions we 
think it appropriate to feel only towards "responsible agents"'(McGeer 2011). On her account these reactive emotions encompass the class of reproachful attitudes broadly conceived. But elsewhere, McGeer and Pettit write that on the normative theory they propose, 'the features that explain failure without counting as excuses are just those factors-those glitches and chances - that are susceptible, according to our injunctive assumptions, to the regulatory effects of our holding one another responsible' (McGeer and Pettit 2015, p. 29). Hence, if one is without excuse one is an appropriate addressee of blame because culpability goes handin-hand with a susceptibility to the capacitating function of resentment and indignation. In contrast, exempting factors imply that a person is not susceptible to the moral-agencycultivating effects of the reproachful attitudes.

The problem on this account, it seems to me, is not that we cannot account for reproachresponsive agents but that we cannot account for the difference between reproach-responsive agents only and agents who meet the threshold for reason-responsiveness. A distinction between reproach-responsiveness and above threshold reasons-responsiveness can help this theory because it marks and explains the different types of responsibility responses that we can find in our practices. We would reproach a young child who behaves objectionably and is reproach responsive, but we would only blame a friend or colleague who can already respond to the reasons that she disregarded.

\section{Anticipating an Objection}

The at times interchangeable use of the terms 'blame' and 'moral address' on CC accounts may suggest to the reader that the class of reproach and the class of blame are to be considered co-extensive on these accounts. I have so far assumed that this is not the case and that the concept of reproach and reproach-responsiveness would be a useful addition to these theories. For most accounts this seems plausible given their descriptions of blame as referring to specifically resentment or indignation and being accompanied by attributions of ill will or disregard for moral reasons. But certain functional accounts of responsibility may suggest that we change what we mean by blaming sentiments so as to include any type of moral reproach.

McGeer especially at times suggests that blame is co-extensive with reproach. On her account, reactive attitudes refer to a broad range of affective disapprovals we may experience in response to perceived norm-transgressions (McGeer 2013, p. 171). In a later paper she discusses how being genuinely deserving of blame on her account means that you are the sort of agent who is due the respect of being seen as a participant who is sensitive to the scaffolding function of reactive attitudes (McGeer 2018). Reproach-responsive agents are due this respect too, so it seems that on her account these agent's would be deserving of blame. Maybe other theorists would opt for a similar response to my proposed addition. ${ }^{5}$

My argument has shown that if one were to equate reproach and blame, one would also have to lower the agency criterion for being an appropriate addressee of blame. Reproach responsiveness suffices for being sensitive to the communicative and cultivating function of reproach broadly conceived. But I advise against this move for three reasons. I think the

\footnotetext{
${ }^{5}$ Miranda Fricker, for example, seems to subscribe to a broad notion of blame when she equates paradigmatic blame with any type of moral correction that achieves shared moral understanding through communication (Fricker 2016). Maureen Sie may also have a broad category of blaming sentiments in mind when she suggests we do and should express resentment towards young children (Sie 2018).
} 
distinction between appropriate reproach and deserved blame usefully refers to different types of evaluations of an agent that can be found in our normative practices, facilitates philosophical debate about these practices, and allows for criticism of these practices. Below I elaborate on these three reasons for maintaining the distinction.

McGeer writes about the sort of capacities that are tracked by blaming attitudes:

It is certainly part of our message that we expect, and indeed, demand, that individuals show one another an appropriate degree of moral regard. But given that our reactive attitudes are sensitive to judgments that we make about whether or not someone is a fitting recipient of these attitudes, the fact that we express them effectively communicates a good deal more. It says to the recipients that we don't despair of them as moral agents; that we don't view them 'objectively' - i.e., as individuals to be managed or treated or somehow worked around; indeed, that we hold them accountable to an ideal of moral agency because we think them capable of living up to that ideal (McGeer 2011, p. 306).

I think her diagnosis of what an expression of reproach conveys to someone is roughly correct here. When we reproach someone, we implicitly convey that we take someone to be able to live up to some sort of expectation or norm. But the specific type of ability to live up to our expectations that we are conveying when we reproach someone matters quite a lot. Conveying or implying that someone 'is already able to do otherwise', is decisively different from conveying that someone can come to live up to moral norms or expectations (Brandenburg 2017). Even though both messages may engage and capacitate the addressee, the first serves to sustain or enhance moral agency whereas the second is a form of enabling or developing moral agency. In both cases we do not 'despair' of someone as a moral participant, but deserved blame is traditionally only associated with the first form of address.

Minimally reproach-responsive agents would be miscategorised by such an account. The recognition that is internal to addressing these agents through reproach is recognition of the person as someone who minimally understands and is responsive to your reproachful response. This response evaluates the other as someone who cares about and is responsive to how what she did affected us. But when we take someone to be deserving of blame, we evaluate the other person as someone who is already able to live up to a moral norm but who has been disregardful of this norm. One reason to distinguish between reproach and blame is to account for these different evaluations of the person, which can accompany or be embedded in a reproachful response.

Please note that this is consistent with the observation that, in our practices, it is not always clear which one of the two one is engaging in. People may waver between reproach and full on blame, or they may be unsure about how they exactly think of the addressee. The conceptual distinction between appropriate reproach and deserved blame in fact helps us to voice such indecisiveness or doubt.

Another reason to distinguish between blame and reproach is for clarity of philosophical debate. Stressing the distinction brings into sharp relief what the disagreement between blamesceptics and CC accounts is actually about. Blame sceptics like Pereboom or Milam claim that -on their typical definitions- blaming attitudes such as resentment or indignation should ideally be abolished because they are harsh and hostile and no person in our world has what it takes to be a deserving target of such attitudes (Milam 2017; Pereboom 2009). But the fact that no one is a deserving target of blame does not also mean that it is never in any other way appropriate 
to address someone by means of reproach. The sort of abilities that would suffice for mild and appropriate forms of reproach differ from the degree of freedom that the sceptics consider to be required for deserved blame (See for example Pereboom 2014).

So, in response to the sceptic CC accounts have to argue that there is something valuable about deserved blame where this refers to the narrow and strong understanding of blaming attitudes, and not just any type of reproach. If a $\mathrm{CC}$ account does not distinguish between appropriate reproach and deserved blame it is unclear whether the narrow and strong notion of blaming attitudes is in fact defended on this account. For example, on McGeer's account it is unclear whether moral communication and cultivation are essential to the stronger blaming attitudes, or may just as well be secured by milder forms of reproach. If strong blaming attitudes are not essential for establishing moral communication and moral agency cultivation, McGeer has not in fact deflected the blame sceptic.

A third reason for distinguishing between appropriate reproach and deserved blame becomes apparent now: if one doesn't distinguish between appropriate reproach and deserved blame, one loses critical potential. On occasions it may be important to criticise someone for unduly blaming a person without thereby denying that this person may be appropriately reproached. If bystanders leave someone wounded in the streets, or if people continue to administer electric shocks to someone when a man in a white coat tells them to do so, expressing reproach as a witness may be an apt form of address communicating the moral import of these transgressions and facilitating moral uptake. But if it is true that these people were not already able to respond to the relevant moral reasons under a range of relevantly similar situations, this should give us pause when it comes feeling indignant and blaming them for what they did.

On other occasions it may be important to criticise someone for withdrawing and repudiating her reproachful responses towards someone based on inabilities that do not in fact justify such a withdrawal of engagement. If the person towards whom reproach is felt would care to know about and be responsive to these feelings, one may have reason to express these feelings despite the person's inability to independently already recognize and respond to a moral reason. The distinction between appropriate reproach and deserved blame allows us to voice these criticisms.

\section{Conclusion}

In this paper I have proposed an addition to $\mathrm{CC}$ accounts. $\mathrm{CC}$ accounts respond to the blamesceptic by arguing that blame is a form of address that tends to cultivate moral understanding and, as a result of that, moral agency in their addressee. By focusing on blame these accounts leave other interesting aspects of our moral practices unattended. I pointed out that reproach more broadly conceived has a very similar role. Reproachful attitudes are akin to blaming sentiments and they may successfully communicate with- and cultivate the agency ofunderdeveloped or compromised agents.

I discussed how adding the criterion of reproach-responsiveness to $\mathrm{CC}$ accounts as an agency-criterion sufficient for reproach (more broadly conceived) usefully supplements and clarifies these accounts. It allows these theories to account for a class of agents who fall below the threshold of reason-responsiveness required for blame, but can still participate in our moral practices and conversations in relevant ways. 
A revisionary $\mathrm{CC}$ account could object that reproachful attitudes equate to blaming attitudes. I argued this objection would be problematic because the distinction between appropriate reproach and deserved blame usefully refers to different types of moral evaluations in our practices, clarifies philosophical debate, and gives a theory critical potential.

I therefore suggest that $\mathrm{CC}$ accounts incorporate a class of agents who are insufficiently competent to be deserving of blame but sufficiently competent to be appropriate addressees of reproach and, in some relevant ways, participants in our responsibility practices.

Acknowledgements Thanks to the VU responsibility group, Ben Matheson, Adam Piovarchy, my supervisors, and two anonymous reviewers for their extensive comments on earlier drafts of this paper.

Funding Funded by The Netherlands Organisation for Scientific Research (NWO). Research project 'Management of the Self: a Humanities Approach to Self-Management in Psychiatry and Psychosomatic Medicine' Project number: $360-20-360$.

OpenAccessThis article is distributed under the terms of the Creative Commons Attribution 4.0 International License (http://creativecommons.org/licenses/by/4.0/), which permits unrestricted use, distribution, and reproduction in any medium, provided you give appropriate credit to the original author(s) and the source, provide a link to the Creative Commons license, and indicate if changes were made.

Publisher's Note Springer Nature remains neutral with regard to jurisdictional claims in published maps and institutional affiliations.

\section{References}

Antony LM (2016) Bias: friend or foe? In: Brownstein M, Saul J (eds) Implicit bias and philosophy, vol 1. Oxford University Press, Oxford, pp 157-190

Bloom P (2012) Moral nativism and moral psychology. In: Mikulincer M, Shaver PR (eds) Herzliya series on personality and social psychology. The social psychology of morality: exploring the causes of good and evil. American Psychological Association, Washington, DC, pp 71-89. https://doi.org/10.1037/13091-004

Brandenburg D (2016) Implicit attitudes and the social capacity for free will. Philosophical Psychology, 29(8). https://doi.org/10.1080/09515089.2016.1235263

Brandenburg D (2017) The Nurturing Stance: Making Sense of Responsibility without Blame. Pacific Philosophical Quarterly, 99(S1). https://doi.org/10.1111/papq.12210

Calhoun C (1989) Responsibility and reproach. Ethics 99(2):389-406

Clarke-Stewart KA (1973) Interactions between mothers and their young children: characteristics and consequences. Monogr Soc Res Child Dev 38(6/7):1-109. https://doi.org/10.2307/1165928

Coates DJ, Tognazzini NA (2013) The contours of blame. In: Coates DJ, Tognazzini NA (eds) Blame: its nature and norms. Oxford University Press, Oxford, pp 3-26

Deigh J (2011) Reactive attitudes revisited. In: Bagnoli C (ed) Morality and the emotions. Oxford University Press, Oxford. Retrieved 19 Feb. 2019, from http://www.oxfordscholarship.com/view/10.1093 /acprof:oso/9780199577507.001.0001/acprof-9780199577507-chapter-10

Fischer JM, Ravizza M (1998) Responsibility and control: a theory of moral responsibility. Cambridge University Press, Cambridge

Fricker M (2016) What's the point of blame? A paradigm based explanation. Noûs 50(1):165-183. https://doi. org/10.1111/nous.12067

Gopnik A (2009) The philosophical baby: what Children's minds tell us about truth, love, and the meaning of life, 1st edn. Farrar, Straus and Giroux, New York

Grusec JE, Goodnow JJ (1994) Impact of parental discipline methods on the child's internalization of values: a reconceptualization of current points of view. Dev Psychol 30(1):4-19. https://doi.org/10.1037/00121649.30.1.4

Grusec JE, Dix T, Mills R (1982) The effects of type, severity and victim of children's transgressions on maternal discipline. Can J Behav Sci 14:276-289

Hieronymi P (2004) The force and fairness of blame. Philos Perspect 18(1):115-148 
Hoffman ML (1983) Affective and cognitive processes in moral internalization: an information processing approach. In: Higgins ET, Ruble D, Hartup W (eds) Social cognition and social development: a sociocultural perspective. Cambridge University Press, New York, pp 236-274

Huebner B (2016) Implicit Bias, reinforcement learning, and Scaffolded moral cognition. In: Brownstein M, Saul J (eds) Implicit bias and philosophy, vol 1. Oxford University Press, Oxford, pp 47-79

Keltner D, Haidt J (2003) Social functions of emotion at four levels of analysis. Cognit Emot 13(5):505-521

Killen M, Smetana JG, Smetana J (eds) (2005) Handbook of moral development, 1st edn. Psychology Press

Levy N (2016) Implicit bias and moral responsibility: probing the data. Philos Phenomenol Res, n/a - n/a. https://doi.org/10.1111/phpr.12352

Lewis M, Haviland-Jones JM, Barrett LF (2010) Handbook of emotions, 3rd edn. The Guilford Press, New York

Macnamara C (2015) Reactive attitudes as communicative entities. Philos Phenomenol Res 90(3):546-569. https://doi.org/10.1111/phpr.12075

McGeer V (2011) Co-reactive attitudes and the making of moral community. In: Langdon R, Mackenzie C (eds) Emotions, imagination, and moral reasoning, 1st edn. Psychology Press, New York

McGeer V (2013) Civilizing blame. In: Coates DJ, Tognazzini NA (eds) Blame: its nature and norms. Oxford University Press, Oxford

McGeer V (2014) P. F. Strawson's consequentialism. In: Shoemaker D, Tognazzini N (eds) Oxford studies in agency and responsibility, vol 2. Oxford University Press, Oxford, pp 64-92

McGeer V (2018) Scaffolding agency: a proleptic account of the reactive attitudes. Eur J Philos 0(0):1-23. https://doi.org/10.1111/ejop.12408

McGeer V, Pettit P (2015) The hard problem of responsibility. In: Shoemaker D (ed) Oxford studies in agency and responsibility. Oxford University Press, Oxford, pp 160-188

McKenna M (2012) Conversation and responsibility. Oxford University Press, Oxford

McKenna M (2017) Power, social inequities, and the conversational theory of moral responsibility. In: Hutchison K, Mackenzie C, Oshana M (eds) Social dimensions of moral responsibility. Oxford University Press, Oxford

Milam P-E (2017) In defense of non-reactive attitudes. Philos Explor 0(0):1-14. https://doi.org/10.1080 /13869795.2017.1298830

Nichols S (2007) After Incompatibilism: a naturalistic defense of the reactive attitudes*. Philos Perspect 21(1): 405-428. https://doi.org/10.1111/j.1520-8583.2007.00131.x

Nichols S, Kumar S, Lopez T, Ayars A, Chan H-Y (2016) Rational learners and moral rules. Mind Lang 31(5): 530-554. https://doi.org/10.1111/mila.12119

Pereboom D (2009) Free will, love, and anger. Ideas Y Valores 58(141):169-189

Pereboom D (2014) Personal relationships and meaning in life. Oxford University Press, Oxford

Pickard H, Ward L (2013) Responsibility without blame: philosophical reflections on clinical practice. In: Fulford KWM, Davies M, Gipps RGT, Graham G, Sadler JZ, Stanghellini G, Thornton T (eds) The Oxford handbook of philosophy and psychiatry. Oxford University Press, Oxford. Retrieved 19 Feb. 2019, from http:/www.oxfordhandbooks.com/view/10.1093/oxfordhb/9780199579563.001.0001/oxfordhb9780199579563-e-066

Pickup, Theroux (2016) Louis Theroux: a different brain, London, BBC documentaries

Sagi A, Hoffman ML (1976) Empathic distress in the newborn. Dev Psychol 12(2):175-176

Schwitzgebel E (2017) On not distinguishing too finely among one's motivations. Retrieved June 21, 2017, from http://schwitzsplinters.blogspot.com/2017/06/on-not-distinguishing-too-finely-among.html. Accessed 20 Feb 2019

Shabo S (2012) Incompatibilism and personal relationships: another look at Strawson's objective attitude. Australas J Philos 90(1):131-147

Shoemaker D (2007) Moral address, moral responsibility, and the boundaries of the moral community. Ethics 118(1):70-108. https://doi.org/10.1086/521280

Shoemaker D (2015) Responsibility from the margins. Oxford University Press, Oxford

Sie M (2018) Sharing responsibility: the importance of tokens of appraisals to our moral practices. In: Hutchison K, Mackenzie C, Oshana M (eds) Social dimensions of moral responsibility. Oxford University Press, Oxford

Smetana JG (1989) Toddlers' social interactions in the context of moral and conventional transgressions in the home. Dev Psychol 25(4):499-508. https://doi.org/10.1037/0012-1649.25.4.499

Smith AM (2007) On being responsible and holding responsible. J Ethics 11(4):465-484

Smith A (2013) Moral blame and moral protest. In: Coates DJ, Tognazzini NA (eds) Blame: its nature and norms. Oxford University Press, Oxford

Strawson PF (2008) Freedom and resentment and other essays. Routledge, New York

Todd P (2012) Manipulation and moral standing: an argument for incompatibilism. Philosophers' Imprint, 12 (March) [Todd 2012 available online]. Permalink: http://hdl.handle.net/2027/spo.3521354.0012.007 
Vargas M (2013) Building better beings: a theory of moral responsibility, 1st edn. Oxford University Press, Oxford

Wallace RJ (1996) Responsibility and the moral sentiments. Harvard University Press, Oxford

Watson G (1993) Responsibility and the limits of evil: variations on a strawsonian theme. In: Fischer JM, Ravizza M (eds) Perspectives on moral responsibility. Cornell University Press, Itaca, pp 119-148

Zahn-Waxler C, Radke-Yarrow M, Wagner E, Chapman M (1992) Development of concern for others. Dev Psychol 28(1):126-136. https://doi.org/10.1037/0012-1649.28.1.126 